Fukushima J. Med. Sci.,

Vol. 56, No. 2, 2010

\title{
[Original Article]
}

\section{HEMATOPOIETIC STEM CELL TRANSPLANTATION IN THE DEPARTMENT OF HEMATOLOGY, FUKUSHIMA MEDICAL UNIVERSITY}

\author{
KAZUEI OGAWA ${ }^{1)}$, HIDEYOSHI NOJI ${ }^{1)}$, MIKI FURUKAWA ${ }^{1)}$, KAYO HARADA-SHIRADO ${ }^{1)}$, \\ YUMIKO MASHIMO ${ }^{1)}$, HIROSHI TAKAHASHI ${ }^{1)}$, HAYATO MATSUMOTO ${ }^{1)}$, \\ SATOSHI KIMURA ${ }^{1)}$, AKIKO SHICHISHIMA-NAKAMURA ${ }^{1)}$, \\ HIROSHI OHKAWARA ${ }^{1)}$, KAZUHIKO IKEDA ${ }^{1)}$, HITOSHI OHTO ${ }^{2)}$ \\ and YASUCHIKA TAKEISHI ${ }^{1)}$ \\ ${ }^{1)}$ Department of Cardiology and Hematology, Fukushima Medical University, Fukushima, Japan, \\ ${ }^{2)}$ Department of Blood Transfusion and Transplantation Immunology, Fukushima Medical University, \\ Fukushima, Japan
}

(Received August 10, 2010, accepted October 26, 2010)

\begin{abstract}
From 1996 to the end of 2009, a total of 114 cases of hematopoietic stem cell transplantation were performed in the Department of Hematology, Fukushima Medical University. We report here a general overview of our results. Allogeneic hematopoietic stem cell transplantation (allo-HSCT) was performed in 37 cases of acute leukemia, 10 of myelodysplastic syndrome, 5 of aplastic anemia, and 5 others. The 5-year survival rate with allo-HSCT was 51.1\%. Autologous hematopoietic stem cell transplantation (auto-HSCT) was performed in 34 cases of malignant lymphoma, 15 of multiple myeloma, and 8 others. The 5 -year patient survival rate was $75.2 \%$ with malignant lymphoma and $46.7 \%$ with multiple myeloma. These results are comparable to those from a nationwide survey in Japan, confirming that our hospital has attained a creditable level as a transplantation center.
\end{abstract}

Key words : Allogenic stem cell transplantation, Autologous stem cell transplantation, Survival curves

\section{INTRODUCTION}

Hematopoietic stem cell transplantation is becoming established as a treatment for refractory blood diseases, with the aim of achieving a cure or prolonging survival. According to a report by the Japan Society for Hematopoietic Cell Transplantation, the number of transplantations performed in Japan had reached 49,100 by $2008^{1)}$. The total number performed in Fukushima Prefecture was 359,269 of which were carried out in our department and the department of pediatrics at our hospital. Our department began autologous hemato- poietic stem cell transplantation (auto-HSCT) in 1996 and allogeneic hematopoietic stem cell transplantation (allo-HSCT) in 1999. By the end of 2009, we had performed a total of 114 hematopoietic stem cell transplantations, the results of which we report here.

\section{METHODS}

The subjects were 114 patients who underwent hematopoietic stem cell transplantation (allo-HSCT, $n=57$; auto-HSCT, $n=57$ ) in our department between July 1996 and December 2009.

小川一英，野地秀義，古川未希，原田佳代，眞下由美子，高橋裕志，松本勇人，木村 哲，七島晶子，大河 原浩, 池田和彦, 大戸 斉, 竹石恭知

Corresponding author : Kazuei Ogawa, MD, PhD E-mail address : kogawa@fmu.ac.jp

http://www.jstage.jst.go.jp/browse/fms http://fmu.ac.jp/home/lib/F-igaku/ 
Using medical records of the above transplantation patients, we surveyed age and disease duration at the time of transplantation, stem cell source, occurrence of graft-versus-host disease (GVHD), complications, and cause of death. The observation period lasted until the end of June 2010. Survival rates were calculated using the Kaplan-Meier method, and the log-rank test was used to test for statistical significance.

\section{RESULTS}

\section{Trends in numbers of transplantations (Fig. 1)}

Auto-HSCTs were started in 1996 and alloHSCTs in 1999. The number of transplantations increased each year, peaking in 2009 with 17 transplantations, including 8 auto-HSCTs and 9 alloHSCTs. HSCTs.

To date, we have not performed any syngeneic

\section{Allo-HSCT}

The clinical characteristics of 57 patients who underwent an allo-HSCT are shown in Table 1. Median patient age at the time of transplantation was 37 years. Fifty-two patients $(91 \%)$ had hematologic malignancies, and the remaining 5 had aplastic anemia (AA). The most common disease was acute myeloid leukemia $(n=24,42 \%)$, followed by acute lymphoblastic leukemia $(n=13,23 \%)$. The stem cell source was bone marrow in 35 cases $(61 \%)$ and peripheral blood stem cells (PBSCs) in 22 $(39 \%)$. Nearly all bone marrow transplantations
(BMTs) were from unrelated donors $(n=33)$. HLA-mismatched transplantations $(n=14)$ were performed with one-locus mismatch. Of 24 cases of transplantation from related donors, 5 were mismatched. They included 2 cases of HLA-A mismatches and 3 of HLA-DR locus mismatches. Nine of the 33 unrelated bone marrow transplantations were HLA-mismatched transplantations, 8 of which were single HLA-DRB1 mismatches. The conditioning regimen before HSCT was a myeloablative stem cell transplantation in 43 patients (75\%) and a non-myeloablative stem cell transplantation in 14 (MDS, $n=6$; AA, $n=4$; malignant lymphoma, $n=2$; AML, $n=1$; myelofibrosis, $n=1)(25 \%)$. Myeloablative conditioning regimens included either total body irradiation (TBI)-based regimens or nonTBI-based regimens. TBI-based regimens mainly consisited of cyclophosphamide $(120 \mathrm{mg} / \mathrm{kg}$ ) plus fractionated TBI (12 Gy), whereas non-TBI-based regimens included busulfan (16 $\mathrm{mg} / \mathrm{kg}$ ) plus cyclophosphamide $(120 \mathrm{mg} / \mathrm{kg})$. Nonmyeloablative conditioning regimens consisted of fludarabine $(125 \mathrm{mg} /$ $\mathrm{kg}$ )-based regimens with or without low-dose TBI (4 $\mathrm{Gy})^{2,3)}$. To prevent GVHD, cyclosporine A (CyA + methotrexate (MTX) was used in HLA-matched related HSCTs and tacrolimus (TAC) +MTX was used in one-locus-mismatched related HSCTs and unrelated bone marrow transplantations. Engraftment was obtained in 51 (94\%) of 54 patients, the other 3 died within 21 days of transplantation. The 3 cases of graft rejection all involved unrelated bone marrow transplantations, i.e., 1 case each of acute myeloid leukemia (AML), acute lymphoblastic leukemia (ALL), and myelodysplastic syndrome

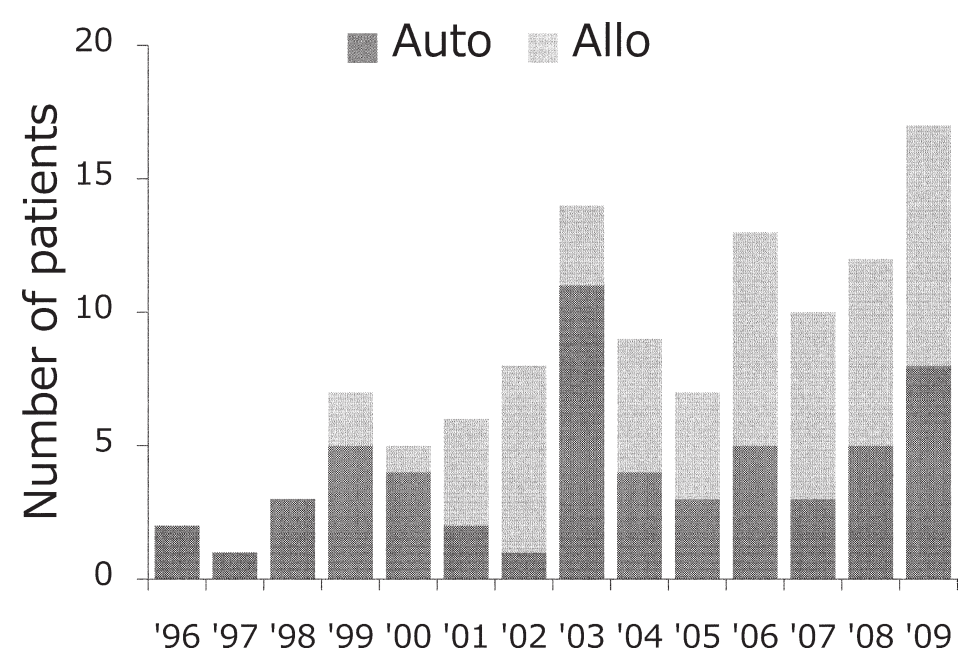

Fig. 1. Trends in number of transplantations.

Auto ; autologous hematopoietic stem cell transplantation, Allo ; allogeneic hematopoietic stem cell transplantation 
Table 1. Clinical characteristics of 57 patients undergoing allogeneic hematopoietic stem cell transplantation

\begin{tabular}{|c|c|c|c|}
\hline Total number & 57 & HLA & \\
\hline Median age (range) & $37(17-60)$ & match/mismatch & $43 / 14$ \\
\hline $\operatorname{Sex}(M / F)$ & $31 / 26$ & Conditioning regimen & \\
\hline Diagnosis & & myeloablative & 43 \\
\hline AML & 24 & nonmyeloablative & 14 \\
\hline First remission & 8 & GVHD prophylaxis & \\
\hline Second remission & 6 & СуA+MTX & 22 \\
\hline relapse/refractory & 10 & $\mathrm{TAC}+\mathrm{MTX}$ & 34 \\
\hline ALL & 13 & СyA+PSL & 1 \\
\hline First remission & 4 & Engraftment & 51 \\
\hline Second remission & 3 & Acute GVHD & \\
\hline Fourth remission & 1 & No & 34 \\
\hline relapse/refractory & 5 & Grade I & 9 \\
\hline MDS & 10 & Grade II & 5 \\
\hline RA & 7 & Grade II & 4 \\
\hline RARS & 1 & Grade IV & 2 \\
\hline RAEB & 2 & $\mathrm{NE}$ & 3 \\
\hline CML & 1 & Chronic GVHD & \\
\hline ML & 3 & No & 34 \\
\hline DLBCL & 2 & Limited type & 8 \\
\hline MCL & 1 & Extensive type & 5 \\
\hline MF & 1 & $\mathrm{NE}$ & 9 \\
\hline $\mathrm{AA}$ & 5 & Survival & \\
\hline Stem cell source & & Alive & 30 \\
\hline $\mathrm{BM}$ & 35 & Dead & 27 \\
\hline related & 2 & relapse/PD & 14 \\
\hline unrelated & 33 & TRC & 13 \\
\hline PBSCs & 22 & & \\
\hline
\end{tabular}

AML; Acute myeloid leukemia, ALL; acute lymphoblastic leukemia, MDS ; myelodysplastic syndrome, RA ; refractory anemia, RARS ; refractory anemia with ringed sideroblasts, RAEB ; refractory anemia with excess blasts, CML ; chronic myelogenous leukemia, $\mathrm{ML}$; malignant lymphoma, DLBCL ; diffuse large B-cell lymphoma, MCL; mantle cell lymphoma, MF myelofibrosis, AA; aplastic anemia, BM; bone marrow, PBSCs; peripheral blood stem cell, CyA; cyclosporine, MTX ; methotrexate, TAC tacrolimus, PSL; prednisolone, NE; not evaluated, PD ; progressive disease, TRC ; transplantation-related complications

(MDS). Two of these 3 cases were transplantations at an advanced stage. Acute GVHD was seen in 20 $(37 \%)$ of 54 evaluable cases, of which acute GVHD of grade II or higher was seen in 11 cases $(20 \%)$. Chronic GVHD was seen in 13 (28\%) of 47 evaluable cases. Twenty-seven patients (47\%) died during the observation period. Causes of death were transplantation-related complications in 13 patients (48\%) and relapse or progression of the original disease in $14(52 \%)$. Causes of death among the transplantation-related deaths were infection in 5 cases, throm- botic microangiopathy in 1 , bronchiolitis obliterans in 1 , GVHD in 2, veno-occlusive disease in 2 , and other causes in 2 .

\section{Survival rate after allo-HSCT}

The overall 5-year survival rate for allo-HSCT was $51.1 \%$ (Fig. 2). As of June 2010, all allo-HSCT patients are alive in continuous complete remission with the exception of 1 patient with CML. Figure 3 shows the survival curve for time after transplantation in acute leukemia patients. Transplantation 


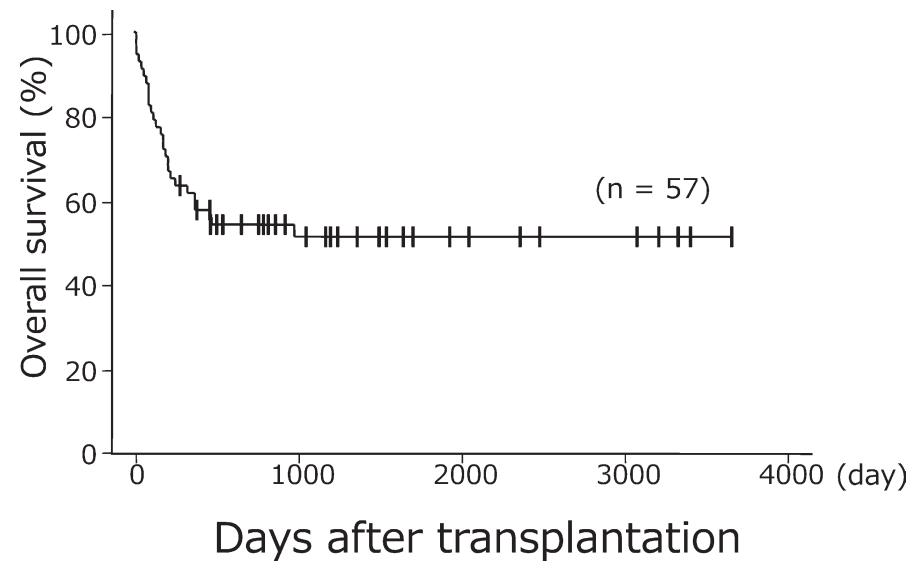

Fig. 2. Probability of overall survival after allogeneic transplantation

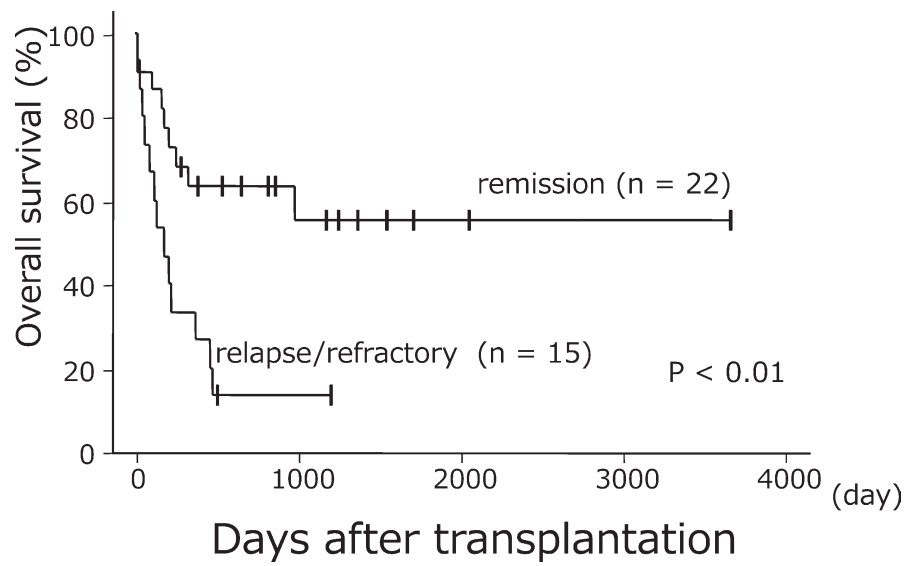

Fig. 3. Probability of overall survival after allogeneic transplantation for acute leukemia.

was for relapse or refractory disease in $10(42 \%)$ of 24 AML patients, and $5(38 \%)$ of 13 ALL patients. The five-year survival rate was $55.4 \%$ in cases of transplantation in complete remission, and $13.3 \%$ in cases of relapse or refractory disease. Figure 4 shows the survival curves by donor. Five-year survival was $39.7 \%$ with HSCT from a related donor, rising to $60.3 \%$ with HSCT from an unrelated donor. This difference, however, was not statistically significant $(P=0.35)$.

\section{Auto-HSCT}

The clinical characteristics of patients with auto-HSCT are shown in Table 2. The underlying disease was malignant lymphoma in 34 cases, multiple myeloma in 15 , and other diseases in 8 [AML, $n=6$; chronic myelogenous leukemia (CML), $n=1$; malignant peripheral nerve sheath tumor, $n=1]$. The median age of malignant lymphoma patients was 47 years, with diffuse large B-cell lymphoma being the most common subtype diagnosed in 16 patients $(47 \%)$. Nine patients $(26 \%)$ died during the observation period, with relapse or progression of the original disease as the cause of death in all cases. The median age of multiple myeloma patients was 57 years. Seven patients $(47 \%)$ showed amyloidosis complications, 4 of whom had cardiac amyloidosis with severe diastolic heart failure or life-threatening ventricular tachycardia. Six patients $(35 \%)$ died during the observation period, with relapse or progression of the original disease as the cause of death in 5 cases and ventricular tachycardia in 1. Autologous peripheral blood stem cell transplantation was performed in 6 AML patients. All transplantations were performed in the first remission, and all patients were alive in continuous complete remission as of June 2010.

\section{Survival rate after auto-HSCT}

The 5-year survival rate of malignant lymphoma patients was $75.2 \%$ (Fig. 5), while that of multiple 


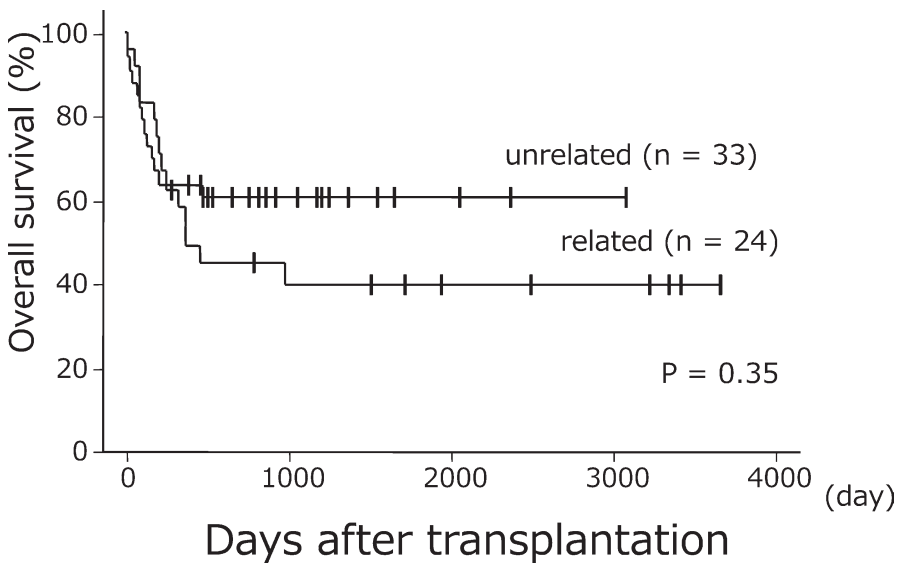

Fig. 4. Probability of overall survival after allogeneic transplantation grouped according to type of donor.

Table 2. Clinical Characteristics of 57 patients undergoing autologous hematopoietic stem cell transplantation

\begin{tabular}{ll}
\hline malignant lymphoma & 34 \\
Medium age (range) & $47(18-65)$ \\
Sex (M/F) & $(23 / 11)$ \\
Classification & \\
DLBCL & 16 \\
FCL & 5 \\
MCL & 1 \\
PTCL & 1 \\
AITL & 1 \\
NK/T & 2 \\
ALCL & 3 \\
LBL & 2 \\
Hodgkin & 3 \\
multiple myeloma & 15 \\
Median age (range) & $57(40-69)$ \\
Sex (M/F) & $(10 / 5)$ \\
Others & 8 \\
AML & 6 \\
CML & 1 \\
malignant peripheral nerve sheath tumor & 1 \\
\hline
\end{tabular}

FCL; follicular lymphoma, PTCL; peripheral T-cell lymphoma, AITL ; angioimmunoblastic T-cell lymphoma, NK/T; NK/T cell lymphoma, ALCL; anaplastic large cell lymphoma, LBL; lymphoblastic lymphoma

myeloma patients was $46.7 \%$ (Fig. 6).

\section{DISCUSSION}

The 5-year survival rate with allo-HSCT in our department was $51.1 \%$, while that for all transplants including, auto-HSCT, was $50.9 \%$ in a 2009 survey reported by the Japan Society for Hematopoietic Cell Transplantation ${ }^{1)}$. Thirty-seven of the 57 who underwent allo-HSCT in our department were leukemia patients. Considering that 15 of 37 acute leukemia patients were transplanted for relapse or progressive disease, and that the source of transplanted cells was an unrelated donor in 33 of the 57 


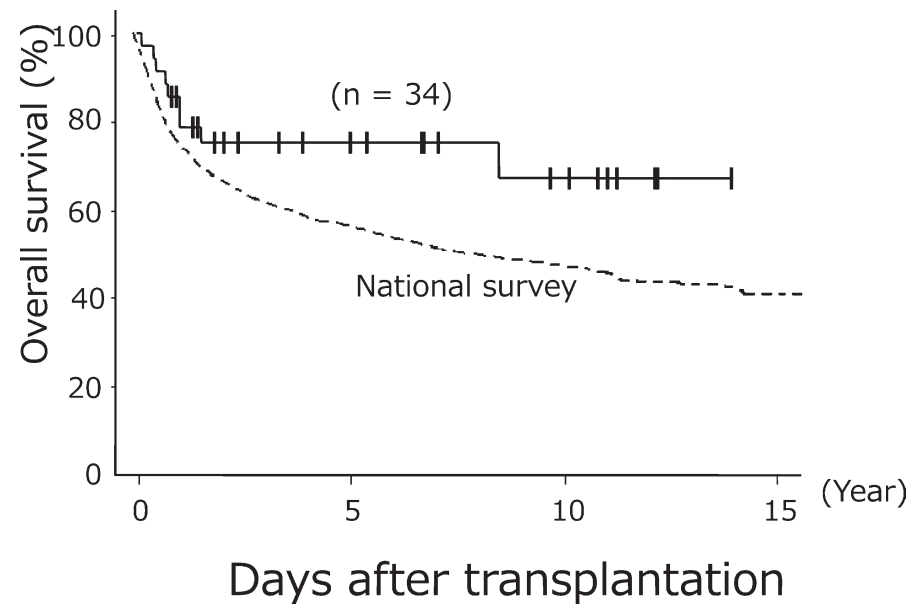

Fig. 5. Probability of overall survival after autologous transplantation for malignant lymphoma. Dotted line shows the survival curve for non-Hodgkin lymphoma from a national survey in Japan.

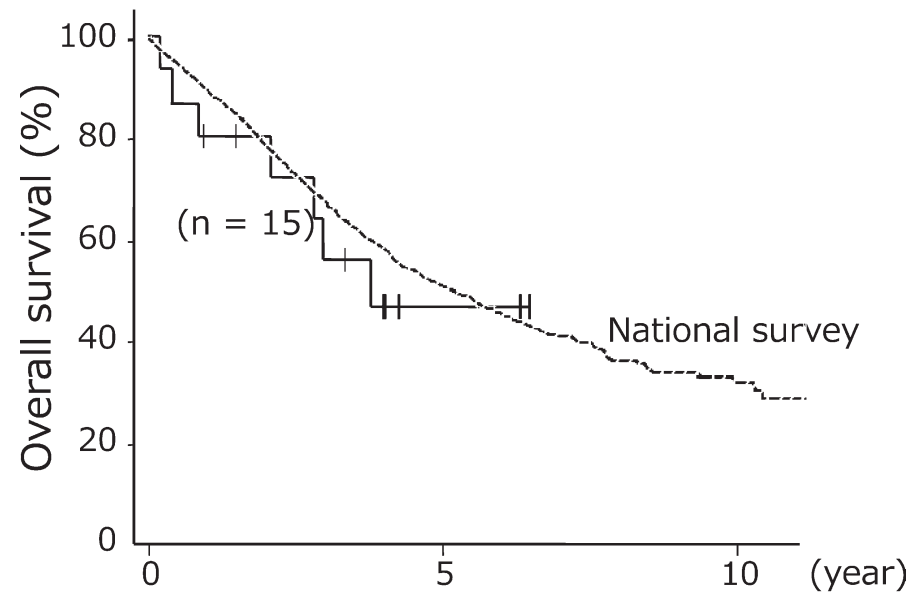

Days after transplantation

Fig. 6. Probability of overall survival after autologous transplantation for multiple myeloma. Dotted line shows the survival curve for multiple myeloma from a national survey in Japan.

patients, the 5-year survival rate for allo-HSCT in our department was a notable achievement, indicating that the standard of medical transplantations in our department would appear to have reached a proficient level. According to a national survey, 5-year survival rates for AML patients in first remission, including related and unrelated transplantations, ranged from $50.2 \%$ to $56.3 \%$. Five-year survival rates in ALL were 46.9-61.1\%. In our department, the 5-year survival rate for acute leukemia patients in remission, including both AML and ALL, was $55.4 \%$. However, considering that only 12 of 22 transplantations were in the first remission, with all others in the second or later remission, the results of allo-HSCT among acute leukemia patients in remission in our hospital seem creditable. In the national survey, 5-year survival rates with transplantations in refractory or relapsed disease were 10-20\%. A similar difficulty involving transplantations for refractory or relapsed disease was experienced in our department.

Transplantations in our department were HLAmismatched in 14 of 57 patients. Although most of the HLA-mismatched transplantations were single HLA-DRB1 mismatches, they had no major effects on the occurrence of acute GVHD ${ }^{4,5)}$. Similarly, we observed no increase in acute GVHD among our single locus mismatch transplantation patients.

In our allo-HSCTs, the 5-year survival rate tended to be higher with unrelated than with related 
transplants. Similar results with related and unrelated bone marrow transplants have been reported in other high-risk patients ${ }^{6)}$. In ALL, disease-free survival with transplantation performed in the first remission using unrelated bone marrow transplantation was reportedly not inferior to that with related bone marrow transplantation ${ }^{7,8}$. The reason for this is thought to be that, despite the high therapyrelated mortality among unrelated transplants, relapse in high-risk patients, including those with ALL, is suppressed by the action of a stronger graftversus-leukemia effect. The reason for the poor results with related transplantations in our patients may have been that 8 of the 12 leukemia patients who received related transplants experienced a relapse or progression of the original disease following transplant. In addition, all our unrelated transplantations cases were bone marrow transplantations, in which TAC was used to prevent GVHD. In contrast, 22 of 24 of our related transplantations cases were peripheral blood stem cell transplantations in which CyA was used to prevent GVHD. Thus, we cannot rule out the possibility that the difference in our results with unrelated and related transplantations reflected differences in GVHD prophylaxis (TAC vs CyA) or stem cell sources (BMT vs PBSCT). In recent years, non-myeloablative stem cell transplantation using reduced-intensity pretransplantation regimens has become widely used $^{2,3)}$. We have also conducted non-myeloablative stem cell transplantation in 14 patients, 11 of whom are surviving in continuous complete remission as of June 2010. Though the large numbers of MDS and AA cases are thought to be one reason for the good results, 2 of the 3 patients who died after transplantation expired from progression of the original disease. The small number of treatmentrelated deaths is therefore a major advantage of nonmyeloablative stem cell transplantation, with patient selection and treatment also being highly important.

According to a national survey, the 5-year survival rate with auto-HSCT for malignant lymphoma is $59.1 \%$, and our hospital exceeded those results ${ }^{11}$. The high quality of our medical transplantations is also supported by the fact that we did not encounter a single transplantation-related death. In recent years, attempts have been made to eliminate malignant cells from the graft with the combined use of rituximab during mobilization and the collection of peripheral blood stem cells (in vivo purging) ${ }^{9}$. We also performed in vivo purging with rituximab during the mobilization and collection of peripheral blood stem cells in 2 patients with malignant lym- phoma, both of whom were surviving in continuous complete remission as of June 2010.

According to a national survey, the 5-year survival rate with auto-HSCT for multiple myeloma is $51.2 \%$. The fact that our hospital was somewhat below those results is mainly attributable to the fact that $47 \%$ of patients experienced complications with amyloidosis with organ damage. However, our patient who had life-threatening ventricular tachycardia underwent auto-HSCT and obtained longterm survival, therefore, we believe that auto-HSCT should be performed aggressively even in patients with amyloidosis complications ${ }^{10)}$.

According to a report by the Japan Marrow Donor Program, 133 patients in Fukushima Prefecture were registered and had received transplantations as of June 2010, but only 62 underwent transplantations inside Fukushima Prefecture. One reason for this may be that our hospital is the only institution in the prefecture approved by the Japan Marrow Donor Program to perform transplantations. The present analysis confirmed that the transplantation results at our hospital are creditable. Our next task is to increase the number of transplant facilities in Fukushima Prefecture while maintaining this level of quality.

\section{ACKNOWLEDGEMENTS}

We wish to thank all the doctors, nurses, and other medical staffs who have been involved in transplantation treatments at our hospital. Furthermore, we are indebted to all the doctors in related hospitals who have referred many patients to us. We also wish to express our appreciation to Dr. Atsushi Kikuta for his invaluable expertise with regard to these medical procedures.

\section{REFERENCES}

1. The Japan Society for Hematopoietic Cell Transplantation. Annual Report of National Survey 2009. (in Japanese)

2. McSweeney PA, Niederwieser D, Shizuru JA, Sandmaier BM, Molina AJ, Maloney DG, Chauncey TR, Gooley TA, Hegenbart U, Nash RA, Radich J, Wagner JL, Minor S, Appelbaum FR, Bensinger WI, Bryant E, Flowers ME, Georges GE, Grumet FC, Kiem HP, Torok-Storb B, Yu C, Blume KG, Storb RF. Hematopoietic cell transplantation in older patients with hematologic malignancies : replacing high-dose cytotoxic therapy with graft-versus-tumor effects. Blood, $97: 3390$ 4400, 2001. 
3. Slavin S, Nagler A, Naparstek E, Kapelushnik Y, Aker M, Cividalli G, Varadi G, Kirschbaum M, Ackerstein A, Samuel S, Amar A, Brautbar C, BenTal O, Eldor A, Or R. Nonmyeloablative stem cell transplantation and cell therapy as an alternative to conventional bone marrow transplantation with lethal cytoreduction for the treatment of malignant and nonmalignant hematologic diseases. Blood, 91: 756-763, 1998.

4. Morishima Y, Sasazuki T, Inoko H, Juji T, Akaza T, Yamamoto K, Ishikawa Y, Kato S, Sao H, Sakamaki H, Kawa K, Hamajima N, Asano S, Kodera Y. The clinical significance of human leukocyte antigen (HLA) allele compatibility in patients receiving a marrow transplant from serologically HLA-A, HLA-B, and HLA-DR matched unrelated donors. Blood, 99 : 4200-4206, 2002.

5. Sasazuki T, Juji T, Morishima Y, Kinukawa N, Kashiwabara H, Inoko H, Yoshida T, Kimura A, Akaza T, Kamikawaji N, Kodera Y, Takaku F. Effect of matching of class I HLA alleles on clinical outcome after transplantation of hematopoietic stem cells from an unrelated donor. N Engl J Med, 339 : 1177-1185, 1998.

6. Kanda Y, Chiba S, Hirai H, Sakamaki H, Iseki T, Kodera Y, Karasuno T, Okamoto S, Hirabayashi N, Iwato K, Maruta A, Fujimori Y, Furukawa T, Mineishi S, Matsuo K, Hamajima N, Imamura M. Allogeneic hematopoietic stem cell transplantation from family members other than HLA-identical siblings over the last decade (1991-2000). Blood, 102 : 1541-1547, 2003.

7. Kiehl MG, Kraut L, Schwerdtfeger R, Hertenstein B, Remberger M, Kroeger N, Stelljes M, Bor- nhaeuser M, Martin H, Scheid C, Ganser A, Zander AR, Kienast J, Ehninger G, Hoelzer D, Diehl V, Fauser AA, Ringden O. Outcome of allogeneic hematopoietic stem-cell transplantation in adult patients with acute lymphoblastic leukemia: no difference in related compared with unrelated transplant in first complete remission. J Clin Oncol, 22 : 2816-2825, 2004.

8. Marks DI, Pérez WS, He W, Zhang MJ, Bishop MR, Bolwell BJ, Bredeson CN, Copelan EA, Gale RP, Gupta V, Hale GA, Isola LM, Jakubowski AA, Keating A, Klumpp TR, Lazarus HM, Liesveld JL, Maziarz RT, McCarthy PL, Sabloff M, Schiller G, Sierra J, Tallman MS, Waller EK, Wiernik PH, Weisdorf DJ. Unrelated donor transplants in adults with Philadelphia-negative acute lymphoblastic leukemia in first complete remission. Blood, 112 : 426-434, 2008.

9. Magni M, Di Nicola M, Devizzi L, Matteucci P, Lombardi F, Gandola L, Ravagnani F, Giardini R, Dastoli G, Tarella C, Pileri A, Bonadonna G, Gianni AM. Successful in vivo purging of CD34-containing peripheral blood harvests in mantle cell and indolent lymphoma: evidence for a role of both chemotherapy and rituximab infusion. Blood, 96 : 864-869, 2000.

10. Yaoita H, Iwai-Takano M, Ogawa K, Suzuki H, Akutsu K, Noji H, Kamiyama Y, Kimura S, Ohtake H, Ishibashi T, Maruyama Y. Attenuation of diastolic heart failure and life-threatening ventricular tachyarrhythmia after peripheral blood stem cell transplantation combined with cardioverter-defibrillator implantation in myeloma-associated cardiac amyloidosis. Circ J, 72 : 331-334, 2008. 